IRA-International Journal of Management \&

Social Sciences

ISSN 2455-2267; Vol.08, Issue 03 (September 2017)

Pg. no. 266-276

Institute of Research Advances

http://research-advances.org/index.php/RAJMSS

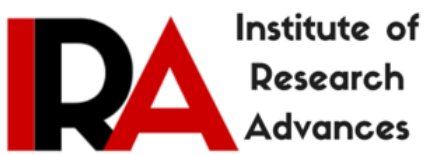

\title{
Impact of Yoga \& Meditation on Psychological Pattern of University Students: A Scientific Paradigm
}

\author{
J. K. Arora ${ }^{1}$, Siddharth Agarwal $^{2}$ \\ 1,2 Technical College, Dayalbagh Educational Institute (Deemed University) \\ Saran Ashram Hospital, Dayalbagh, Agra 28200, India.
}

Type of Review: Peer Reviewed.

DOI: http://dx.doi.org/10.21013/jmss.v8.n3.p5

\begin{abstract}
How to cite this paper:
Arora, J.K., Agarwal, S. (2017). Impact of Yoga \& Meditation on Psychological Pattern of University Students: A Scientific Paradigm. IRA-International Journal of Management \& Social Sciences (ISSN 24552267), 8(3), 266-276. doi:http://dx.doi.org/10.21013/jmss.v8.n3.p5
\end{abstract}

(C) Institute of Research Advances.

\section{(cc) BY-NC}

This work is licensed under a Creative Commons Attribution-Non Commercial 4.0 International License subject to proper citation to the publication source of the work.

Disclaimer: The scholarly papers as reviewed and published by the Institute of Research Advances (IRA) are the views and opinions of their respective authors and are not the views or opinions of the IRA. The IRA disclaims of any harm or loss caused due to the published content to any party.

Institute of Research Advances is an institutional publisher member of Publishers Inter Linking Association Inc. (PILA-CrossRef), USA. The institute is an institutional signatory to the Budapest Open Access Initiative, Hungary advocating the open access of scientific and scholarly knowledge. The Institute is a registered content provider under Open Access Initiative Protocol for Metadata Harvesting (OAI-PMH).

The journal is indexed \& included in WorldCat Discovery Service (USA), CrossRef Metadata Search (USA), WorldCat (USA), OCLC (USA), Open J-Gate (India), EZB (Germany) Scilit (Switzerland), Airiti (China), Bielefeld Academic Search Engine (BASE) of Bielefeld University, Germany, PKP Index of Simon Fraser University, Canada. 


\begin{abstract}
To improve the quality of life, there has been the search of strategies for handling stress, and subjective well-being. These explorations have led us to ancient disciplines such as Yoga, which combine the physical elements of a healthy lifestyle with mental peace. It integrates the personality by bringing body-mind-soul coordination in a well-balanced way. The present paper is aimed to create awareness of the need of regular practice of Yoga and Meditation among the matured group of students at university level which will certainly help to improve the qualities of their mind for not only worldly achievements and success in life but also in attains, the ultimate goal of life which is spiritual upliftment. This scientific study compared 'impact of yoga alone and yoga with meditation on alteration of psychological profile of university level students. It was predicted that practitioners' psychological wellbeing would vary as a function of their parameters like stress, ESP, PSI-Q, and Working Memory. Result was statically analyzed using null Hypothesis. The experimental results are very optimistic in that yoga \& meditation combined practice can alter an individual's social, self, physical and emotional wellbeing .It also indicates that practitioners with yoga with spiritual intentions reported significantly higher psychological wellbeing compared with practitioners doing yoga alone.
\end{abstract}

Keywords: Extra Sensory Perception (ESP), PSI-Q, Working Memory, Consciousness.

\title{
I. Introduction:
}

Among the various approaches to improve the quality of life, there has been the search for better strategies for handling stress, and improving the subjective well- being. In search of this global problem, we studied ancient disciplines such as Yoga, which combine the physical elements of a healthy lifestyle with potent prescriptions for abiding mental peace. Yoga is a state of steadiness at emotional level, balance of concentration, physical fitness, and detachment at mental level and homeostasis at body level. It integrates the personality by bringing body- mind-soul coordination in a well-balanced way. Thus Yoga is a skillful trick to calm down the mind and to establish union of body with mind. It includes concentrating one's consciousness on physical body through controlled breathing and postures. Yoga certainly helps a person to recognize the qualities of the individual mind, using. In fact, the physical well-being is a good feature but Yoga should not remain confined to just physical well-being. If yoga practices are only limited with merely performing various Asans like Padmasana, Sidhasana, Bhugasana, Dhanurasana, Vajraasana.One can secure bodily health. Learning Yoga as physical training, to secure benefits of merely bodily and mental well-being, in a very laudable manner should not be the only aim in the context for which it is known for ages. The real goal should be the spiritual upliftment from one hierarchy of spirituality to a higher level with for complete release from bondage of body and mind attendant full benefits can be secured only by the methods of Trancedental Meditation, which in which spirit entity gets absorbed with the internal sound, sitting in a natural posture. Many studies have been conducted in past for ESP (Radin1987, Tanous and Donnelly 2009) The first laboratory experiment for the trance - telepathy ESP was conducting by(Radin2003).( Lewis CS 2008)have investigated to 'fix' illnesses, injuries, and remedial conditions. Nurturing these beliefs, promotional leaflets which are distributed by local clubs often describe yoga as a practice which "can be helpful to correct muscular skeletal imbalances, develop core strength and flexibility, improve breathing patterns, release stress and tension, increase energy and vitality. Implicit measurement of positive and negative future thinking as a predictor of depression symptoms and hopelessness consciousness and Cognition, have given by (LivKosnes et. al. 2013). Whilst some practitioners consider asana to constitute an alternative form of exercise, others are drawn to this postural yoga as they believe it to offer an effective form of physical therapy. (Ullman, Krippner \& Feldstein 1966 ) have investigated experimentally induced telepathic dreams conducted two studies using EEG-REM monitoring. long-term yoga practitioners in the United States investigated musculo-skeletal and mental health improvements (Birdee et. al.2008). Electrophysiological studies were conducted on ESP in dreams, considering sex differences in seventy four telepathy sessions by (Krippner 1970). (Moliver N S,et al.) have suggested about Yoga experience as a predictor of psychological wellness in women over 45 years.

Mindfulness in particular improves attention, working memory capacity, and reading comprehension as per studies done by (Agarwal et al, 2013, Kramer et.al.2013). Studies have also shown that there is the significant effect of Yoga and Meditation on different dimensions of consciousness quotient (Ahuja, 2013).The biology of meditation reveals that after three months meditation, participant's had higher level of neurotransmitters in their blood, although 
the exact nature of the relationship between neurotransmitters and meditation have yet to be revealed. Increase in alpha rhythm amplitude and decrease in beta-wave activity was found among mediators. Similarly decreased heart and respiratory rates, improved memory, attention and concentration were found among mediators, as compared to the non-mediators as well as before and after meditation in the same subjects (Anand 2013).The first scientific attempts to enlighten the phenomenon of consciousness appeared only in psychology through development of psychophysics and theories of personality. The hierarchy of biological neural networks at sub-cellular micro tubular cytoskeleton level had lead to a kind of interface between neural and quantum co-relates [Hameroff 1994].

The psycho-physiological correlates of several techniques includes altering states of consciousness, demonstrating more or less characteristic features in Meridian (Psycho)Therapies, Microwave Resonance Relaxation, Autogenic Training, Transcendental Meditation, Musicogenic States, Healer/Healed Interactions, and Alertness/Drowsiness. Such a tool might be useful in evaluating the effectiveness of different techniques for stress reduction and for altering expressions of consciousness. Fundamental field-related macroscopic Hopfield-like quantum information basis of the underlying quantum-holographic paradigm were considered, with implication that whole psychosomatics might be considered as a quantum hologram, both on the level of individual and collective consciousness. This enables quantum-holographic hierarchical fractal coupling of various hierarchical levels in nature [Rakovic et al 2009].Meditative and non-meditative spiritual experiences of 31 practitioners following different spiritual traditions were explored and identified. Spiritual experiences from 16 subjects were collected by semi-structured interview method and the remaining data was collected from published literature. Both types of data are subjected to thematic analysis. An attempt was made to segregate various aspects of a spiritual experience and termed as 'Issues'. Ninety three spiritual issues were traced from the data. In order to facilitate better understanding of the type and range of spiritual experiences, these 'issues' are combined and categorized into themes (Kandi 2012). The IQs (Intelligent Quotent) and Indexes are the most reliable numbers from the WAIS III (Wechsler Adult Intelligence Scale) for measuring Verbal IQ, Performance IQ and Full Scale IQ. Inter-rater reliability of WAIS-III test is also very good. The new concept of working memory clarifies the short-term memory concept by focusing more on how we attend, rehearse and manipulate information in temporary storage (Engle 2002).

In the Maimonides dream research experiments, scientists involved two experimental controls, the subject and agent persons who had to spend the night in the laboratory for dream telepathy experiment. The psychic ability of subject was recorded by examining him immediately after REM period of sleep (Sherwood and Roe, 2002)

The concept of quantum mechanics and wave function reduction of the whole cognitive process was developed into a computer algorithm. Feynman propagator quantum approach includes an analogous mathematical formalism as the Hopfield associative neural network [Perus 1996].

Meditation leads to a higher state of consciousness characterized by sense of deep relaxation and loss of selfawareness. In it, the attention is focused on an object in the environment such as flower or a figure, a rhythmic physical motion of the body (such as breathing) or a mantra (a chant or phrase that mediator repeats). Or contemplation of an adaptor repletion of spiritens name, various forms of meditation practices are prevalent like concentrative meditation, opening up meditation, mindfulness meditation (Feldman, 2002).

Research has increasingly focused on the benefits of meditation in everyday life and performance. Mindfulness in particular improves attention, working memory capacity, and reading comprehension (Agarwal et al, 2013).

Using SQUID (Super Conducting Quantum Interface Devices) based measurements at the time of meditation cumprayer session at Dayalbagh, Agra reveals that atmosphere becomes quite focused during meditation and the magnetic field in the vicinity also arises. Even immediately after meditation there is the kind of residual effect and serenity continues to prevail (Satsangi and Sahni, 2012). (Arora et.al. 2015) have investigated effect of Meditation and Cognitive Factor for the measurement of Level of Consciousness: ANN Computational Model. Effects of meditation on Chakra Energy and Hemodynamic Parameter have given by (Arora et.al.2015).Have seen the impact of Physical Exercise and Transcendental Meditation on Physiological parameters: An ANN Modelling.

\section{MATERIALS AND METHODS:}

The study was conducted on 20 (Hostellers) healthy male volunteers between the age group of 16-22 years M=19.5 yrars,SD=6.5) of Technical College Dayalbagh Educational Institute. . The criteria to take part also involved regular yoga practice willingly and enthusiastically for their overall betterment.. All the target psychological parameters of 
the subjects were recorded through various tests like Advanced ESP test, Precognition test, Psi- Q test while Stress was recorded in power lab system software. All the practitioners were initially given a warm up light exercise for 5 minutes daily before the yoga.

Practitioners performed yogic asanas (postures) such as Anulom-Vilom, KapalBharti, Bhujangasana, Vajrasana, Siddhasana and Shavasana for 20 minutes during morning hours. The shavasana was intermittently practiced for about 2 minutes after completing four asanas in this sequence under the supervision of two qualified instructors for one month. After completion of one month all psychological parameters were recorded namely as middle data,

After one month participants were to practiced Yoga Asana (postures) such as Anulom-Vilom,KapalBharti, Bhujangasana, Vajrasana, Siddhasana and Shavasana for 20 minutes during morning hours. The shavasana was intermittently practiced for about 2 minutes after completing four asanas in this sequence under the supervision of two qualified instructors. Then make body perfect for Concentration to relax toes, then feet, ankles, calves, heart, lungs, neck, hands. Then the brain and mind are relaxed by concentrating on self-spirit. The thoughts of mind will be removed by concentrating on breathe. And then they were approaching for Transdental Meditation ( TM ) 30 minutes daily. It was performed by concentrating first on breath, so as to divert senses away from the physical world. The eyes could be kept closed. The students were concentrating on God, Guru, Sound, Name or any particular Object. Students can follow their own religious beliefs for considering object of concentration to achieve higher level of consciousness for two months namely post data. (Table 1) Data for this study was collected via hard copies of the questionnaire and an online survey replicating test. The questionnaire was distributed as a hard copy to yoga practitioners

\begin{tabular}{|c|c|c|c|c|c|c|c|c|c|c|c|c|}
\hline Name & Pre Stress & Pre Psi Q & Pre ESP TEST & Pre Working Memory Test & Mid Stress & Mid PSi Q & Mid ESP TEST & Mid Working Memory Test & Post Stress & Post Psi Q & Post ESP TEST & Post Working Memory Test \\
\hline M. Mebin P.S. & 13 & 72 & 1.7932 & 2.25658 & 11 & 78 & 2.79844 & 2.34525 & 3 & 89 & 4.7081 & 4.9137 \\
\hline K. Kantikonda & 14 & 47 & 2.4124 & -0.86859 & 10 & 49 & 2.9124 & -0.93451 & 10 & 47 & 4.8933 & 4.0376 \\
\hline Ansh & 29 & 49 & -0.8838 & 0.57654 & 20 & 51 & 0.8068 & 1.87213 & 16 & 49 & 3.7089 & 3.82352 \\
\hline Anurag Chetan & 21 & 53 & 1.3421 & 0.25868 & 19 & 55 & 4.1081 & 0.80313 & 17 & 57 & 3.9903 & 4.8933 \\
\hline Hirdesh & 20 & 40 & -0.7823 & 1.75345 & 12 & 43 & -0.6763 & 2.34515 & 12 & 40 & 4.9023 & 4.7999 \\
\hline Akash & 25 & 54 & -0.7324 & -0.55467 & 20 & 51 & 3.9923 & -0.99013 & 20 & 54 & 4.0376 & 3.82379 \\
\hline Kamal & 16 & 58 & 2.7545 & -0.88576 & 17 & 57 & 2.8045 & -0.67823 & 9 & 61 & 3.6031 & 4.9023 \\
\hline Krishna & 25 & 54 & 1.7932 & 1.58866 & 25 & 60 & 1.7999 & 1.90423 & 20 & 62 & 4.9137 & 2.9964 \\
\hline Aarat & 33 & 44 & 3.0312 & -0.78655 & 29 & 47 & 4.6203 & 0.01364 & 24 & 51 & 4.9053 & \\
\hline Nirakh & 24 & 52 & 1.7764 & 0.87578 & 21 & 52 & 2.0456 & 1.06732 & 18 & 54 & 3.8238 & 3.7632 \\
\hline Nirath & 18 & 56 & 1.2463 & 0.87764 & 16 & 59 & 1.8346 & 1.74513 & 11 & 60 & 4.7999 & 4.9137 \\
\hline Pravendra & 30 & 46 & -0.7634 & 2.12566 & 18 & 47 & 3.9023 & 2.33522 & 20 & 53 & 3.9126 & 3.7089 \\
\hline Ravinder & 19 & 52 & -0.8817 & 1.59099 & 10 & 56 & 4.2345 & 1.60291 & 11 & 68 & 3.9764 & 4.9023 \\
\hline S. Prasad & 18 & 51 & -0.8973 & 1.76578 & 16 & 55 & 1.8973 & 1.97623 & 14 & 57 & 4.9231 & 4.7999 \\
\hline S. Ramesh & 15 & 56 & -0.6254 & 1.56459 & 15 & 55 & 4.0961 & 1.30413 & 12 & 55 & 2.7365 & 2.7637 \\
\hline S. Surya & 26 & 47 & 4.8974 & 0.36788 & 26 & 51 & 3.8992 & 1.06123 & 20 & 54 & 3.7632 & 2.7365 \\
\hline Sanjay & 13 & 55 & -0.6301 & 0.88575 & 11 & 57 & -0.6617 & 0.90132 & 10 & 55 & 3.9126 & 4.9231 \\
\hline Vijay & 10 & 59 & 0.9834 & -0.56778 & 8 & 63 & 3.8933 & -0.47038 & 7 & 66 & 4.9979 & 4.7081 \\
\hline Arpit & 27 & 51 & -0.1253 & 1.86778 & 21 & 55 & 3.8079 & 2.12271 & 20 & 54 & 2.9964 & 4.8933 \\
\hline Yomkesh & 35 & 42 & 1.8324 & 0.25668 & 28 & 44 & 3.6031 & 0.67301 & 27 & 48 & 3.7632 & 3.7089 \\
\hline
\end{tabular}

- Stress were recorded in power lab system.

- ESP (Extra sensory Peception) of the practitioners were measured, through Advanced ESP Test OnlinePSIQ Level were computing in twelve Dimensions, i.e. Psychic, Psychokinesis, Pre Cognition, Scrying(Crystal Grazing), Auras, Mediumship, Channelling, Past Life, Luck, Intution, Imagination, Paranormal Belief, Credulity, ESP Divided into three Scales (Strong, Moderate, Little). [Noel Sheehy; Antony J. Chapman; Wendy A. Conroy (2002)].

- Working Memory was measured through intelligence and cognitive ability in Students by The Wechsler Adult Intelligence Scale (WAIS, David Wechsler1955). 


\section{Result and Discussion:}

Results Data was analyzed using Statistical Package for Social Sciences, Version 23.0.Experimental intervention of yoga and meditation based on Hierarchical clustering Analysis to identify relatively homogenous groups of subjects on selected characteristic using HCA Algorithm Considering Divisive, Resulting to a construction of a Hierarchical Structure (dendogram) which is depicting in Fig 1.a,b (respectively) formation of clusters through the straight forward method.

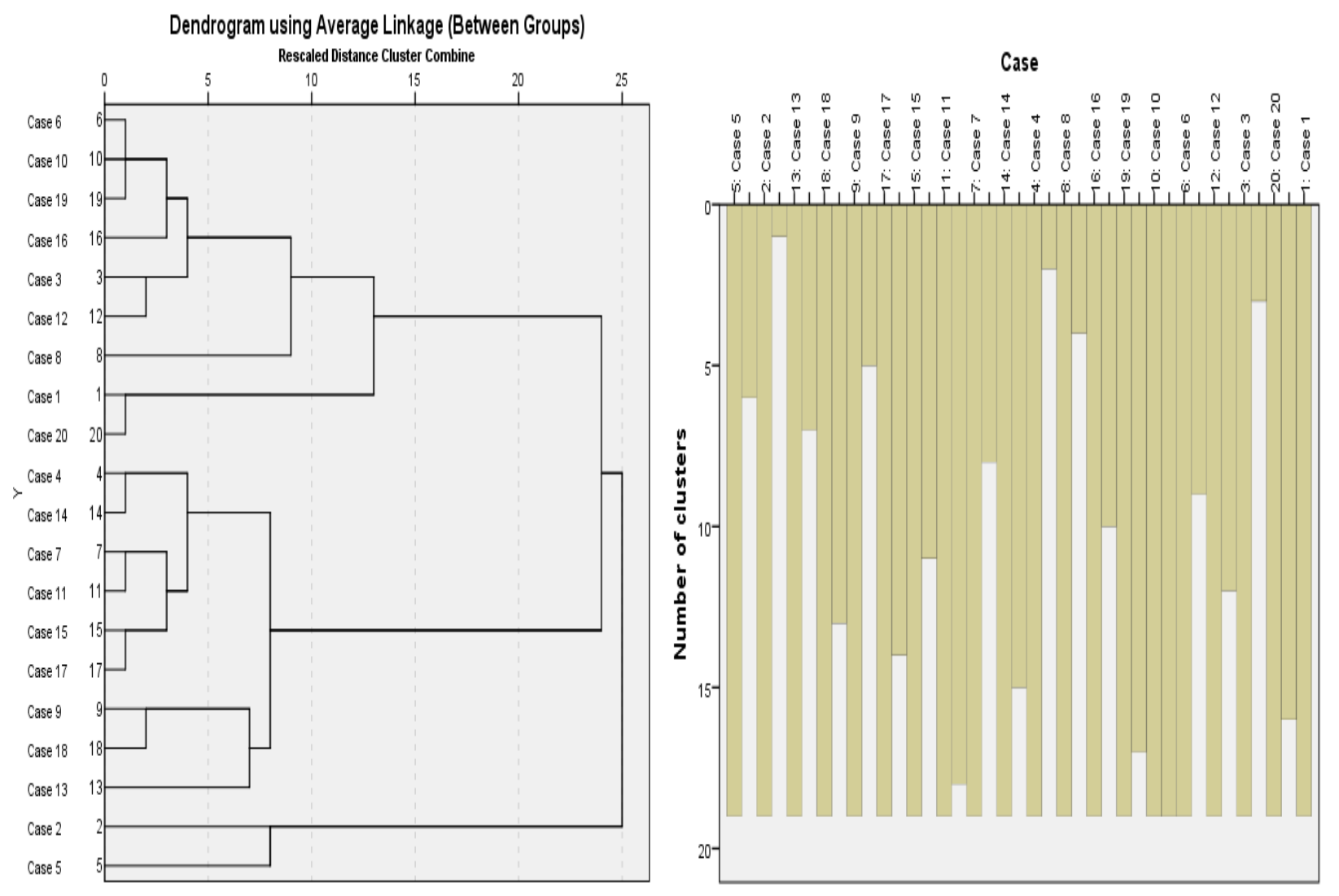

- Impact of yoga and meditation on psychological profile of the subjects were statistically analyzed the data through ANOVA with Tukey's Test for Nonadditivity to estimate the power to which observations must be raised to achieve additivity $=-.369$. and Grand Mean $=20.0515839$

(table 2) 
Table

ANOVA with Tukey's Test for Nonadditivity

\begin{tabular}{|c|c|c|c|c|c|c|c|}
\hline & & & Sum of Squares & $\mathrm{df}$ & Mean Square & $\mathrm{F}$ & Sig \\
\hline \multicolumn{3}{|c|}{ Between People } & 5652.700 & 59 & 95.808 & & \\
\hline \multicolumn{3}{|c|}{ Between Items } & 334014.034 & 7 & 47716.291 & 528.232 & .000 \\
\hline & & Nenadditivity & $18322.831^{\mathrm{a}}$ & 1 & 18322.831 & 397.645 & .000 \\
\hline \multirow[t]{3}{*}{ Within People } & Residual & Balance & 18984.288 & 412 & 46.078 & & \\
\hline & & Total & 37307.119 & 413 & 90.332 & & \\
\hline & Total & & 371321.153 & 420 & 884.098 & & \\
\hline Total & & & 376973.853 & 479 & 787.002 & & \\
\hline
\end{tabular}

Grand Mean $=20.0515839$

Table 3

- Depitcs Intraclass correlation coefficients using a consistency definition-the between-measure variance is excluded from the denominator variance. Two-way mixed effects model where students effects are random while measures effects are fixed. This estimate is computed assuming the interaction effect is absent, because it is not estimable otherwise.

Intraclass Correlation Coefficient

\begin{tabular}{|c|r|r|r|r|r|r|r|}
\hline \multirow{2}{*}{ Table 3 } & Intraclass & \multicolumn{2}{|c|}{$95 \%$ Confidence Interval } & \multicolumn{4}{|c|}{ F Test with True Value 0 } \\
\cline { 3 - 8 } & Correlation & Lower Bound & Upper Bound & Value & df1 & \multicolumn{1}{c|}{ df2 } & \multicolumn{1}{c|}{ Sig } \\
\hline Single Measures & $.008^{\mathrm{a}}$ & -.034 & .071 & 1.061 & 59 & 413 & .363 \\
Average Measures & $.057^{\mathrm{c}}$ & -.352 & .379 & 1.061 & 59 & 413 & .363 \\
\hline
\end{tabular}

Paired t-tests were applied for this study due to its robust features to evaluate the degree of deviation from these assumptions in order to assess the quality of the results. The null hypothesis assumes that the true mean difference between the paired samples were zero. In this study, all observable differences were explained by random variation, as a parametric procedure to estimate (Stress, ESP, PSI-Q, WM). Note: $\mathrm{N}=$ number of participants; $d=$ Cohen's d effect size, ${ }^{*} \mathrm{p}<0.01$, one-tailed, **p $<0.001$, one-tailed

Table 1: Paired Samples t-tests looking at Initial and Continued, Spiritual and Physical Intentions.

Another statistically significant finding was that level of wellbeing intentions increase over time, from when practitioners initially take up yoga $(\mathrm{M}=1.082$; $\mathrm{SD}=1.05)$ to when their practice becomes more established $(\mathrm{M}=$ 2.161; $\mathrm{SD}=2.29), \mathrm{t}(.-11.5$ to 27.2$), \mathrm{df}=19, \mathrm{p}<0.005$ (one-tailed). This is in line with the hypothesis that wellbeing level become more salient as a practitioner continues with their yoga with Meditational practice comparative to only yoga.,. However, the t-test conducted to see if there was a difference between initial and continued physical intentions did not reach statistical significance, $\mathrm{t}=-11.5, \mathrm{p}=0.10506 ; \mathrm{d}=19$. Result indicates that practitioner's physical intentions did not change over time from when they first took up the practice to their motivations for continuing. In terms of psychological wellness, a significant difference was found between overall wellbeing levels between practitioners who were regularly participating in yoga with Meditation practice with respect to yoga only as shown in Figure 4, practitioners who reported more spiritual than physical intentions, when considering why they continue to practice yoga with Meditation, had significantly higher levels of overall psychological wellbeing compared to yoga only physical than spiritual intentions $(M=20.3, S D=10.97)$.

- The test was performed under these assumptions.

- The dependent variable must be continuous (interval/ratio).

- The observations are independent of one another. 
- The dependent variable should be approximately normally distributed.

- The dependent variable should not contain any outliers.

- Paired Samples t-tests looking at Initial and Continued, level of well being and Physical Intentions.

\begin{tabular}{|c|c|c|c|c|c|c|c|c|c|}
\hline \multicolumn{10}{|c|}{ Paired Samples Test } \\
\hline \multicolumn{2}{|c|}{ Table 4} & \multicolumn{5}{|c|}{ Paired Differences } & \multirow[t]{3}{*}{$t$} & \multirow[t]{3}{*}{$\mathrm{df}$} & \multirow{3}{*}{$\begin{array}{c}\text { Sig. } \\
\text { (2- } \\
\text { tailed) }\end{array}$} \\
\hline & & \multirow[t]{2}{*}{ Mean } & \multirow[t]{2}{*}{ Std. Deviation } & \multirow[t]{2}{*}{$\begin{array}{l}\text { Std. Error } \\
\text { Mean }\end{array}$} & \multicolumn{2}{|c|}{$\begin{array}{c}\text { 95\% Confidence Interval of the } \\
\text { Difference }\end{array}$} & & & \\
\hline & & & & & Lower & Upper & & & \\
\hline Pair 1 & $\begin{array}{l}\text { VAR00001- } \\
\text { VAR00002 }\end{array}$ & -29.70000000 & 11.53530051 & 2.57937161 & -35.09868682 & -24.30131318 & -11.514 & 19 & .000 \\
\hline Pair 2 & $\begin{array}{l}\text { VAR00003- } \\
\text { VAR00004 }\end{array}$ & -29.70000000 & 11.53530051 & 2.57937161 & -35.09868682 & -24.30131318 & -11.514 & 19 & .000 \\
\hline Pair 3 & $\begin{array}{l}\text { VAR00005- } \\
\text { VAR00006 }\end{array}$ & -29.70000000 & 11.53530051 & 2.57937161 & -35.09868682 & -24.30131318 & -11.514 & 19 & .000 \\
\hline Pair 4 & $\begin{array}{l}\text { VAR00007- } \\
\text { VAR000008 }\end{array}$ & .60807500 & 1.81342582 & .40549434 & -.24063441 & 1.45678441 & 1.500 & 19 & .150 \\
\hline Pair 5 & $\begin{array}{l}\text { VAR00009- } \\
\text { VAR00010 }\end{array}$ & 2.55794500 & 2.33222440 & .52150123 & 1.46643038 & 3.64945962 & 4.905 & 19 & .000 \\
\hline Pair 6 & $\begin{array}{l}\text { VAR00011- } \\
\text { VAR00012 }\end{array}$ & 4.15738500 & .67908212 & .15184738 & 3.83956478 & 4.47520522 & 27.379 & 19 & .000 \\
\hline Pair 7 & $\begin{array}{l}\text { VAR00013- } \\
\text { VAR00014 }\end{array}$ & .24733950 & 1.21294225 & .27122213 & -.32033495 & .81501395 & .912 & 19 & .373 \\
\hline Pair 8 & $\begin{array}{l}\text { VAR00015- } \\
\text { VAR00016 }\end{array}$ & 1.02864950 & 1.05683741 & .23631603 & .53403437 & 1.52326463 & 4.353 & 19 & .000 \\
\hline Pair 9 & $\begin{array}{l}\text { VAR00017- } \\
\text { VAR00018 }\end{array}$ & 4.28785500 & .70350915 & .15730943 & 3.95860258 & 4.61710742 & 27.257 & 19 & .000 \\
\hline
\end{tabular}

\section{Table 5}

- Overview to examine the effect of yoga and meditation on psychological parameters. There were different architectures, tested for optimum model for the given data (For description of data some values were missing within the range, it could be found).

\section{Overall Summary of Missing Values}

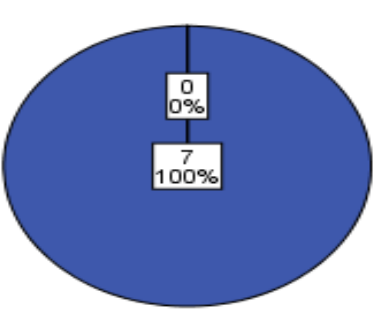

Variables

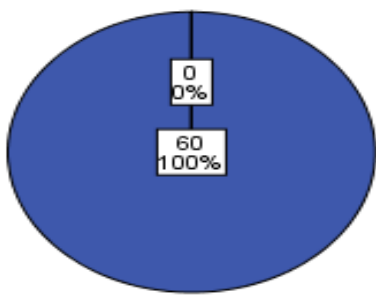

Cases

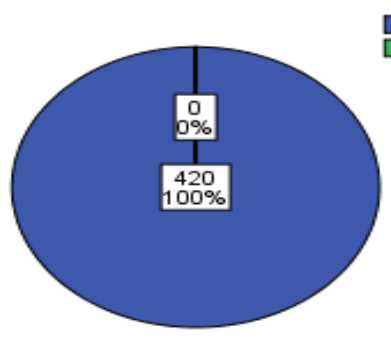

Values 
- Optimum model was found for the diffract of the variables lying in the range RMSE (0.460 to 2.660), MAPE (2.969 to 154.379$)$, BIC -1.6652 to 2.107 while stationary mean was 0.642 . For level of signification $\mathrm{p}<0.05$.

Model Fit

\begin{tabular}{|c|c|c|c|c|c|c|c|c|c|c|c|}
\hline \multirow[t]{2}{*}{ Fit Statistic } & \multirow[t]{2}{*}{ Mean } & \multirow[t]{2}{*}{ SE } & \multirow[t]{2}{*}{ Minimum } & \multirow[t]{2}{*}{ Maximum } & \multicolumn{7}{|c|}{ Percentile } \\
\hline & & & & & 5 & 10 & 25 & 50 & 75 & 90 & 95 \\
\hline $\begin{array}{l}\text { Stationary } \\
\text { R-squared }\end{array}$ & .642 & .428 & $\begin{array}{r}1.110 \mathrm{E}- \\
016\end{array}$ & .860 & $\begin{array}{r}1.110 \mathrm{E}- \\
016\end{array}$ & $\begin{array}{r}1.110 \mathrm{E}- \\
016\end{array}$ & .213 & .854 & .859 & .860 & .860 \\
\hline R-squared & .642 & .428 & $\begin{array}{r}1.110 \mathrm{E}- \\
016\end{array}$ & .860 & $\begin{array}{r}1.110 \mathrm{E}- \\
016\end{array}$ & $\begin{array}{r}1.110 \mathrm{E}- \\
016\end{array}$ & .213 & .854 & .859 & .860 & .860 \\
\hline RMSE & 1.710 & .959 & .406 & 2.660 & .406 & .406 & .723 & 1.887 & 2.520 & 2.660 & 2.660 \\
\hline MAPE & 53.871 & 69.961 & 2.959 & 154.379 & 2.959 & 2.959 & 4.614 & 29.074 & 127.926 & 154.379 & 154.379 \\
\hline MaxAPE & 248.187 & 373.996 & 9.493 & 799.952 & 9.493 & 9.493 & 13.083 & 91.651 & 639.826 & 799.952 & 799.952 \\
\hline MAE & 1.334 & .725 & .324 & 2.044 & .324 & .324 & .598 & 1.485 & 1.920 & 2.044 & 2.044 \\
\hline MaxAE & 4.246 & 2.519 & .919 & 6.918 & .919 & .919 & 1.695 & 4.573 & 6.470 & 6.918 & 6.918 \\
\hline $\begin{array}{l}\text { Normalized } \\
\text { BIC }\end{array}$ & .816 & 1.691 & -1.655 & 2.107 & -1.655 & -1.655 & -.946 & 1.407 & 1.988 & 2.107 & 2.107 \\
\hline
\end{tabular}

We are aware of our thoughts, emotions and perceptions. When we enter altered/higher states of consciousness, our mental state differs significantly from waking consciousness. Some altered state of consciousness such as sleeping and dreaming occur naturally. Others such as those induced by drug or hypnosis are triggered by deliberate attempts to alter one's state of consciousness; yoga \&meditation is an altered state of consciousness characterized by sense of deep relaxation and loss of self-awareness. In it, the attention is focused on an object in the environment such as flower or a figure, a rhythmic physical motion of the body (such as breathing) or a mantra (a chant or phrase that mediator repeats), repletion of speritens name or contemplation of an adapt or heating internal sounds. (Sriramamurti et. al. 2013) have discussed about the different stages of Spiritual Consciousness. In this pilot study, done initially after one month of yoga practice, the practitioners did not show significant result change in psychological patterns but there was significant improvement in various dimensions of psychological parameters after 3 Months of practice of yoga and meditation simultaneously (Arora et. al. 2013).The consciousness of experienced practitioners also increased considerably with the regular practice of yoga and meditation. These findings corroborate the results of previous studies that report meditation promotes both physical and mental wellbeing and contributes to the development of positive emotional traits (Brown \& Ryan, 2003).Increase in rhythm amplitude and decrease in beta-wave activity in EEG are found among mediators. It is shown that the level of extra sensory perception significantly enhanced with yoga and meditation process compared with yoga only. (Hansel et.al. 1989, Jarvis et. al.2002, Murphy et. al 1971)Similarly decreased heart and respiratory rates, improved memory, attention and concentration were found among mediators as compared to the non-mediators as well as before and after meditation in the same subjects (Anand 2013). Studies have also shown that there is the significant effect of Yoga and Meditation on different dimensions of consciousness quotient (Ahuja, 2013). 


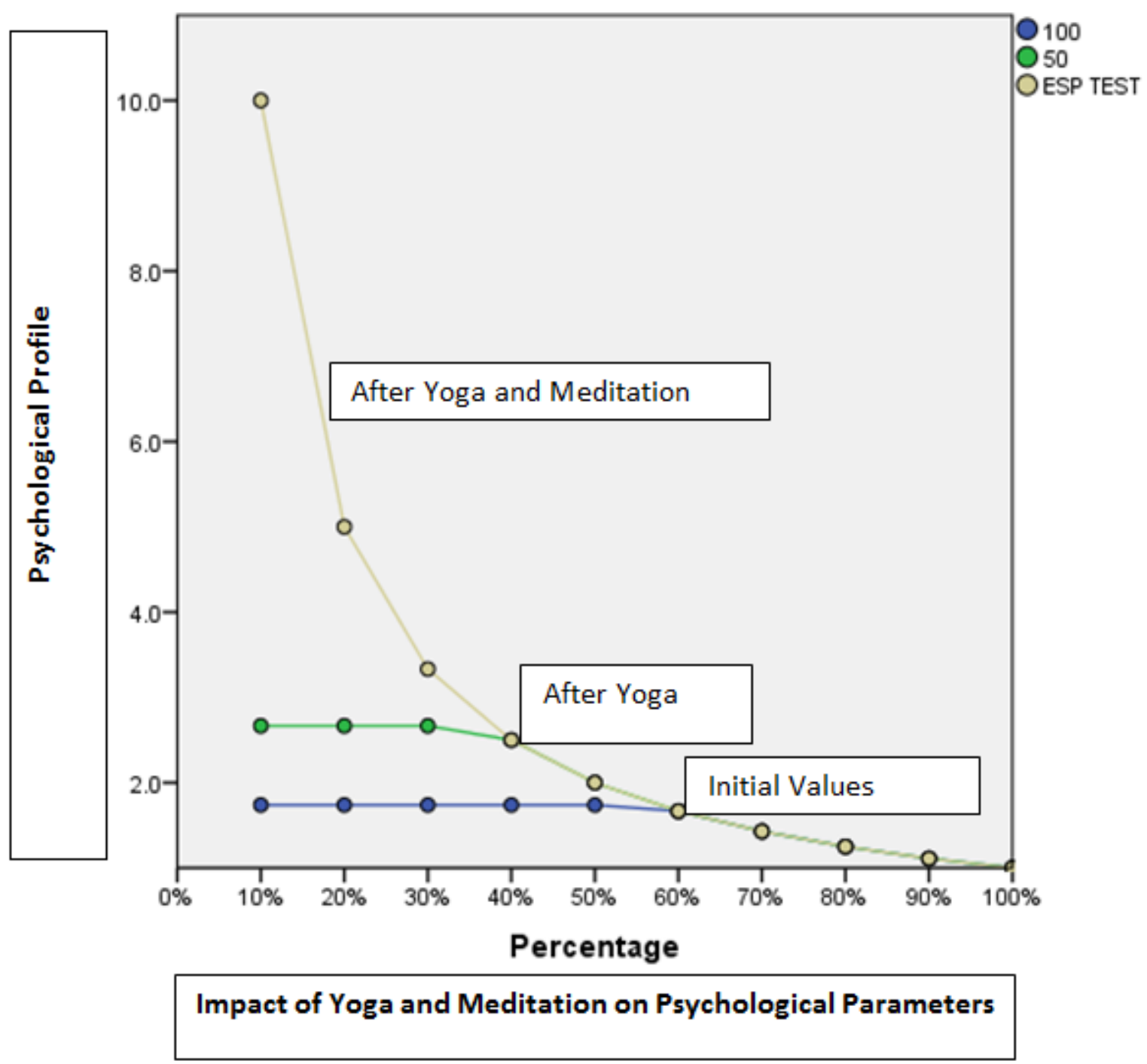

IV. Sensitivity Analysis:

A sensitivity analysis was conducted to determine the degree of effectiveness of variables during Yoga \& Meditation. Performance of the group of input vectors included ESP, Stress, PSI-Q \& WM The degree of effectiveness of variables were found connected psychologically. The developed model was examined for its ability to performance of experimental data which was not forming the part of the training program. The comparison results of desired outputs and inputs are shown in Fig. 2 


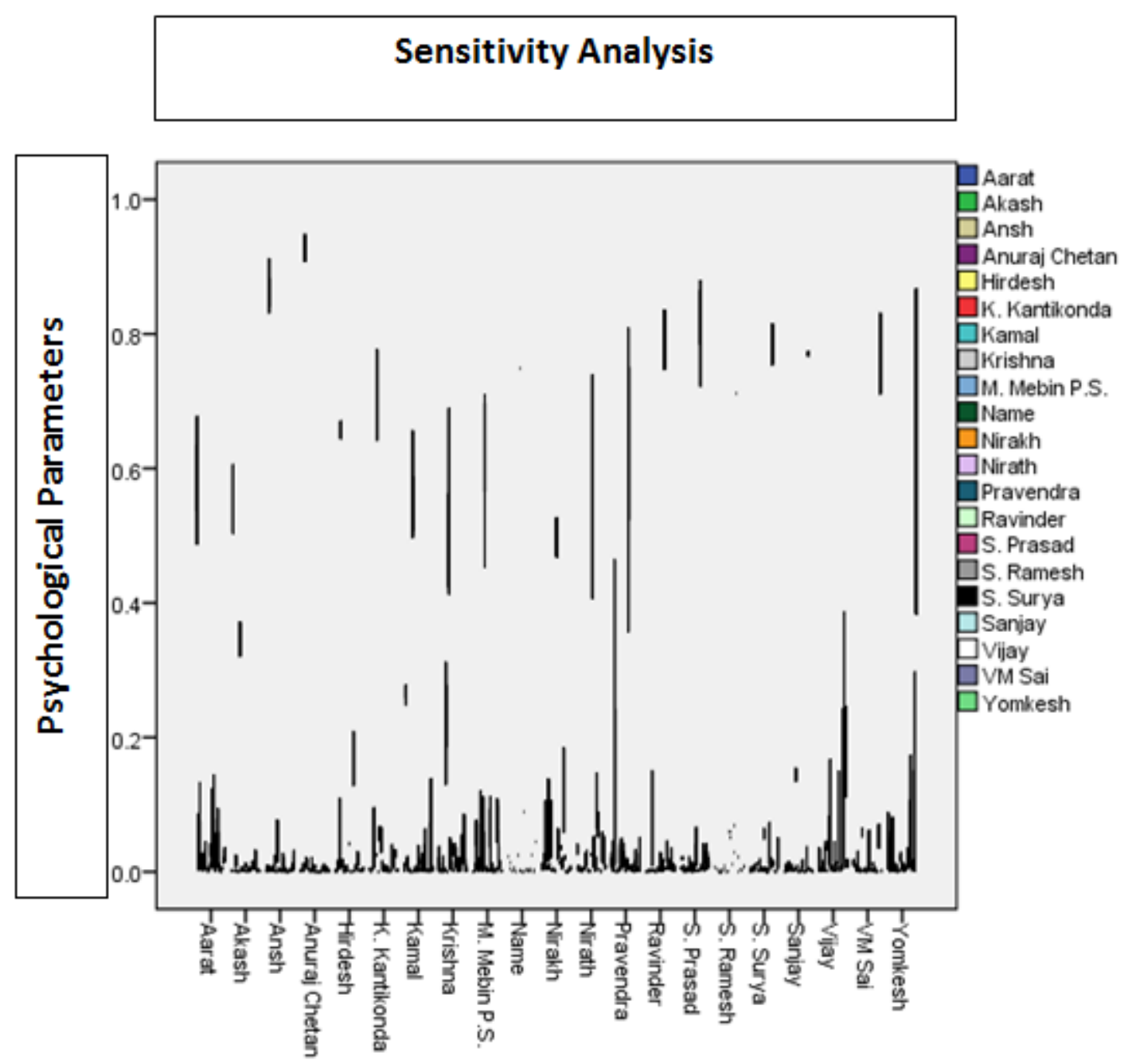

\section{Conclusion:}

Physio-psycho correlations are considered an effective scientific tool for the evaluation of the level of consciousness. Our motivation and focal theme of the paper is to evaluate the impact of fundamentals of ethical life style on the level of consciousness followed by scientific justifications based on psycho physiological parameters in university students. The objective of the study was to examine the effect of yoga and meditation on the enhancement of the psychological patterns of the university level students. Twenty participants took part in the pilot study. The participants of the pilot study highlighted that the practice of yoga and meditation is more effective for pre-initiates, i.e. who these are not trained for any meditational practice. The enhancement of various dimensions of consciousness level, through yoga and meditation as reported in other researches account for better cognitive factors and consciousness as a whole. The experimental results are very optimistic in that yoga \& meditation combined practices can improve an individual's social, self, physical and emotional consciousness setting towards the positive results.

A longer duration of practice \& study may have significant effect on mental and spiritual consciousness.

\section{ACKNOWLEDGMENT}

I am highly grateful to all the participants of this paper for giving support throughout to complete my work successfully and Director, Prof. P.K. Kalra for his valuable guidance of, Dayalbagh Educational Institute, Agra, I present my gratitude to my wife Sherry Arora for the encouragement and support. And lastly, my special thanks to my student M. Mebin Panamkuttiyiel Saumain, III year Mechnical Engineering, for all his efforts. 


\section{References}

[1] Radin, D. I. Precognition of probable versus actual futures: Exploring futures that will never be, Journal of Research in Parapsychology, 1-5. (1987).

[2] Radin, D.I., \& Nelson, R.D. (2003) Meta-analysis of mind-matter interaction experiments: 1959-2000, Healing, Intention and Energy Medicine, 39-48.

[3] Tanous and Donnelly, The first laboratory experiment for ESP was conducted by Lundholm and Rhine for the trance telepathy (2009)

[4] Lewis CS Life chances and wellness: Meaning and motivation in the 'yoga market'. Sport in Society: Cultures, Commerce, Media, Politics 11: 535-545.(2008)

[5] LivKosnes, Robert Whelan, and Louise A. Implicit measurement of positive and negative future thinking as a predictor of depression symptoms and hopelessness consciousness and Cognition, 22(3), 898-912. (2013).

[6] Ullman, Krippner \& Feldstein, Experimentally - induced Telepathic Dreams, Google Books, 1966.

[7] Ullman et.al., Experimentally induced telepathic dreams to study using EEG-REM monitoring, 1966.

[8] Moliver N, Mika E M, Chartrand MS, Haussmann RE, Khalsa SBS, et al. Yoga experience as a predictor of psychological wellness in women over 45 years. International Journal of Yoga 6: 11-19.(2013)

[9] Agarwal, S S. Enhancing intuition through Yoga and meditation. Proceedings of TSC, Dayalbagh Educational Institute, Agra.(2013)

[10] Kramer S S. Ulrich W. Weger, Dinkar Sharma. The effect of mindfulness meditation on time perception, Consciousness and Cognition, 22(3).846-852. (2013).

[11] Ahuja, Effect of yoga and meditation on different dimensions of consciousness-Proceedings of TSC 2013.Dayalbagh Educational Institute, Agra.

[12] Anand Das, Effect of meditation ('OM' chanting) on alpha EEG and galvanic skin response: Measurement of an unaltered state of consciousness. Proceedings of TSC. Dayalbagh Educational Institute, Agra.( 2013).

[13] Hameroff S R. Quantum coherence in microtubules, A neural basis for emergent consciousness. J. Consciousness Studies. 1, 91-118, 1994.

[14] Raković D. Transitional states of consciousness as a biophysical basis of transpersonal transcendental phenomena. Int. J. Appl. Sci. \& Computat. 7. 174-187. (2009).

[15] S. Kandi .Meditation and mindfulness Achtsamkeit Altes Wissenschafftneue Wissenshaft. Ancient knowledge creates new science. 111-128. (2012)

[16] Engle, Short term memory - "how we attend, rehearse and manipulate information in temporary storage,"(2002).

[17] Sherwood and Roe, Dream Telepathy Test for the improvement of ESP level in human subject,(2002).

[18] Perus M., Neuro-quantum parallelism in mind-brain and computers, Informatica, 20, 173-183, (1996).

[19] Feldman, Various forms of meditation practices are prevalent concentrative meditation, opening up meditation, mindfulness meditation, (2002).

[20] Satsangi, P.S., Sahni V. Cosmic consciousness hierarchization: Analytic, experimental and experiential. Towards a Science of Consciousness.. Proceedings of TSC, Dayalbagh Educational Institute, Agra.9-14,(2012).

[21] JK Arora, MM Srivastava, Siddartha Agrawal. Effect of Meditation and Cognitive Factor for the Measurement of Level of Consciousness: ANN Computational Model International Journal of Science and Research (IJSR) ISSN (Online): 2319-7064 | Vol. (4)(2013)

[22] JK Arora, DK Chaturvedi, Effect of meditation on Chakra Energy and Hemodynamic Parameters. International Journal of Computer Applications (0975 - 8887) Vol.126 - No.12, September 2015 52(2013)

[23] Noel Sheehy; Antony J. Chapman; Wendy A. Conroy. Biographical Dictionary of Psychology. Taylor \& Francis. pp. 409-. ISBN 978-0-415-28561-2.(2002)

[24] Birdee, G. S., Legedza, A. T., Saper, R. B., Bertisch, S. M., Eisenberg, D. M. \& Philips, R.S..Characteristics of yoga users: results of a national survey.Journal of General InternalMedicine,23(10), 1653-1658.(2008)

[25] Sriramamurti.P, Prashant. P \&Mohan. A, Spiritual Consciousness, New Age Books, Dayalbagh Press, Agra.(2013).

[26] Hansel, C.E.M. , The Search for Psychic Power: ESP and Parapsychology Revisited. New York: Prometheus Books, (1989).

[27] Matt Jarvis, J. R. ,Zener Cards. In Key Ideas in Psychology (pp. 117, 118), (2002).

[28] Murphy, J. Psychic Perception; The Magic of Extrasensory Power, (1971).

[29] R. Bhardwaja, S.P Singh, M.M. Srivastava, J.K.Arora (2013). Effect of Meditation and Cognitive Factor for the Measurement of Level of Consciousness: ANN Computational Model, International Journal of Science and Research (IJSR) ISSN (Online): 2319-7064 Index Copernicus Volume(4). 